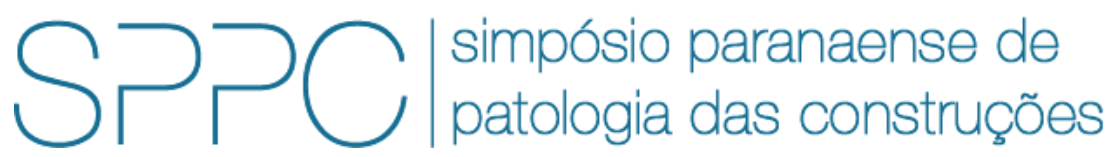

ISSN 2526-7248 artigo 2SPPC2003, pp. 486-499, 2017

\title{
Reforço de fundação da Ponte Manoel Ribas, caso de obra
}

\author{
Luiz Henrique Felipe Olavo', Roberto José Gazda² e Maurício Gazda ${ }^{3}$ \\ ${ }^{1}$ Mestre em Constr. Civil, ENSOLO Eng. Solos e Fund. Ltda, luiz@ensolo.com.br \\ 2 Engenheiro Civil, ENSOLO Eng. Solos e Fund. Ltda, robertogazda@ensolo.com.br \\ ${ }^{3}$ Engenheiro Civil, ENSOLO Eng. Solos e Fund. Ltda, mauricio@ensolo.com.br
}

\begin{abstract}
Resumo: Mostra-se o caso de obra do reforço de fundações da Ponte Manoel Ribas, sobre o Rio Iguaçu, localizada em União da Vitória, Paraná. A ponte possuía fundação direta, sendo apoiada sobre sapatas assentes em siltito abaixo do material incosolidade do leito do rio. Abaixo do siltito há a presença de arenito, o qual foi dragado para obtenção de agregado para a construção civil, causando o recalque de sapatas da ponte. Para o reforço de fundação foram adotadas estacas raiz em rocha, sendo que foi necessária a perfuração de um bloco de fundação existente com sapata diamantada, sendo este bloco um bloco provisório utilizado para a construção da ponte e abandonado. Os pilares reforçados foram posteriormente seccionados e macaqueados para renivelamento do tabuleiro da ponte.
\end{abstract}

Palavras-chave: Ponte Manoel Ribas, Reforço de Fundações, Estacas Raiz.

Abstract: The study case of the foundation reinforcement for the Manoel Ribas bridge is shown. The bridge is located over the Iguaçu river, in União da Vitória, Paraná. The bridge was founded over spread foundations, resting over a siltstone, that lays below the loose soil of the river bed. Below the siltstone there is sandstone that was dredged in order to obtain aggregates for the concrete industry, causing the settlement of some footings of the bridge. Root piles were adopted for foundation reinforcement and it was necessary to drill one existing foundation block with the use of a diamond bit. This block was a provisional block used during the bridge construction. The reinforced columns were later cut and suspended in order to recompose the level of the bridge's deck.

Keywords: Manoel Ribas bridge, Foundation reinforcement, Root Piles. 


\section{Introdução}

Apresentam-se os trabalhos executados para reforço das fundações da Ponte Manoel Ribas, localizada em União da Vitória, sobre o Rio Iguaçu. A ponte havia recalcado, o que levou à sua interdição para o tráfego, além de ter causado o desnivelamento do seu tabuleiro.

Além do reforço de fundações, feito com o uso de estacas raiz, foi necessário realizar o renivelamento do tabuleiro da ponte. Ao final dos serviços a mesma foi reaberta ao tráfego.

\section{Histórico}

A ponte Manoel Ribas foi a primeira ponte rodoviária construída sobre o Rio Iguaçu para permitir o acesso à cidade de União da Vitória. A mesma teve sua construção iniciada em 1937 pela Companhia Construtora Nacional S.A., sendo concluída em 1944. A ponte é constituída por uma estrutura em arco, em concreto armado, sendo que houve um acidente durante a primeira vez em que se tentou montar o arco, com as suas formas vindo a cair em decorrência de uma cheia do rio. O primeiro arco tinha suas formas apoiadas sobre o leito do rio, em uma ponte branca, com estacas de madeira. Posteriormente foram executados blocos de fundação provisórios para apoio de duas torres por sobre as quais se passaram cabos de aço de forma a suspender as formas de madeira utilizadas para a concretagem do arco como em uma ponte pênsil. Estes blocos ainda estão localizados sob a ponte e são visíveis [1].

A ponte situa-se em um local onde o leito do rio é composto por um siltito [2]. Devido à boa característica mecânica deste siltito, a ponte é fundada sobre fundação direta.

Sob o siltito encontra-se um arenito. A região de União da Vitória é carente em agregados finos para a indústria do concreto e tradicionalmente as jazidas de areia eram as barrancas dos rios, as quais eram dragadas. Os exploradores de areia da região descobriram que o siltito poderia ser perfurado pela draga e o arenito subjacente dava origem a uma areia com poucos finos e relativamente uniforme, a qual poderia suprir a indústria do concreto. Desta forma, começou-se a exploração deste arenito. A exploração inicialmente ocorreu de forma desordenada, o que levou à remoção de material sob a fundação da ponte, causando a subsidência da rocha de apoio da mesma e consequentemente o recalque de seus apoios. Devido a este fato, a dragagem nas proximidades da ponte foi proibida e o tráfego sobre a mesma foi proibido, prejudicando o abastecimento da cidade.

Em decorrência do recalque e consequente desnivelamento do tabuleiro da ponte, foi previsto um reforço das fundações da mesma. Para este reforço foram previstas estacas raiz, de modo a possibilitar a perfuração da rocha branda superficial e o embutimento das estacas na rocha coerente subjacente. Além disso, a solução com estacas raiz permitiria a perfuração de eventuais obstáculos existentes devido ao acidente com o primeiro arco da ponte. Não foram observados recalques para os apoios do arco em si e somente foi previsto o reforço dos demais pilares. 


\section{Estacas raiz}

A estaca raiz foi desenvolvida na década de 1960, na Itália, pelo engenheiro Fernando Lizzi e recebeu inicialmente o nome, em italiano, de pali radice [3]. A técnica consiste na execução de uma estaca com o uso de uma sonda rotativa, a qual introduz, por rotação, um revestimento no solo, o qual é dotado de uma sapata na sua extremidade que tem a função de desagregar o solo. A perfuração é feita com o auxílio de um fluido de perfuração, cujo fluxo pode ser direto, quando o mesmo é injetado por dentro do revestimento e retorna por fora trazendo os detritos de perfuração ou inverso, quando o mesmo é sugado pelo interior do revestimento com os detritos e tem seu nível completo na superfície. O fluido tem por função trazer os detritos de perfuração que são desagregados pela sapata [4]. Além disso, o seu fluxo ascendente pelo espaço anelar entre o revestimento e o solo dá-se com alta velocidade e turbulência, garantindo a erosão do solo em um padrão irregular e garantindo a rugosidade do fuste da estaca e boa aderência com o solo [4]. $O$ processo executivo de uma estaca raiz pode ser visto na figura 1.

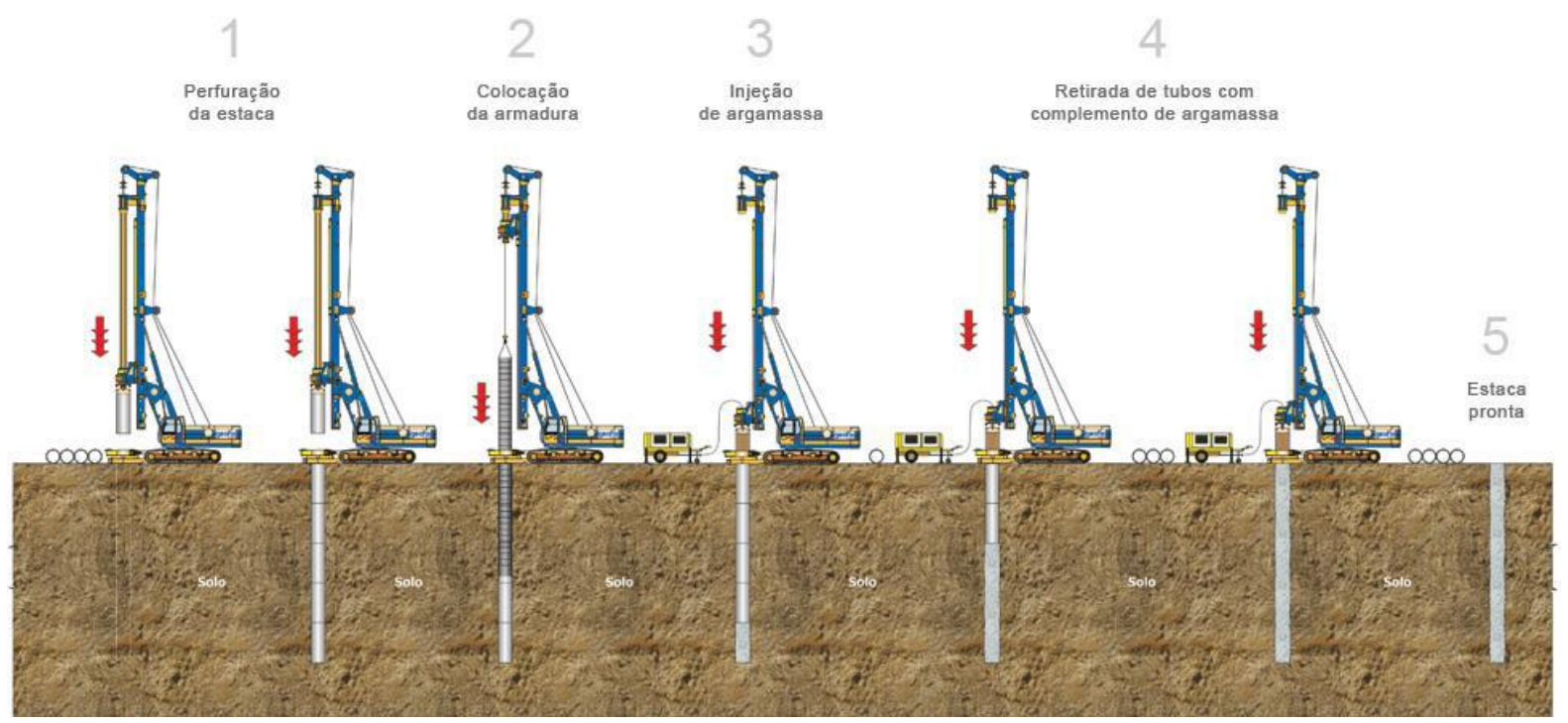

Figura 1: Processo executivo de estacas raiz [5]

O fluido de perfuração pode ser composto por água limpa, água de retorno da perfuração (com reaproveitamento) ou ainda pode receber adições de bentonita ou polímeros à base de poliacrilamida [4]. As adições têm o objetivo de aumentar a viscosidade do fluido, o que melhora sua capacidade de trazer os detritos de perfuração e a limpeza do furo. Por outro lado, o aumento da viscosidade reduz a turbulência no espaço anelar, podendo prejudicar a rugosidade do fuste e a sua escolha deve ser feita cuidadosamente.

A estaca raiz inicialmente era utilizada formando reticulados. Lizzi [3] concluiu que desta forma a capacidade do reticulado era superior à capacidade das estacas isoladas somadas (fig. 2). No início eram utilizados reticulados de estacas raiz de pequeno diâmetro e estes reticulados eram utilizados como um reforço do terreno sob fundações superficiais com problemas, ganhando notoriedade em reforços de fundação. Com o desenvolvimento de equipamentos de maior porte as mesmas passaram a ser utilizadas em blocos de estacas, da mesma forma como os demais 
tipos de estacas. Atualmente estão disponíveis no mercado máquinas para executar estacas raiz com até $600 \mathrm{~mm}$ de diâmetro acabado, sendo que a norma de fundações já referencia estacas com diâmetro até 450mm [6], [7], [8], [9]. Sodré et. al. [10], porém, encontraram efeitos de escala importantes para as estacas raiz, onde a sua aderência com o solo reduz-se à medida que o diâmetro aumenta, fato este também observado por Cabral [11]. Desta forma, recomenda-se cuidado quando forem necessárias estacas de diâmetro maior.
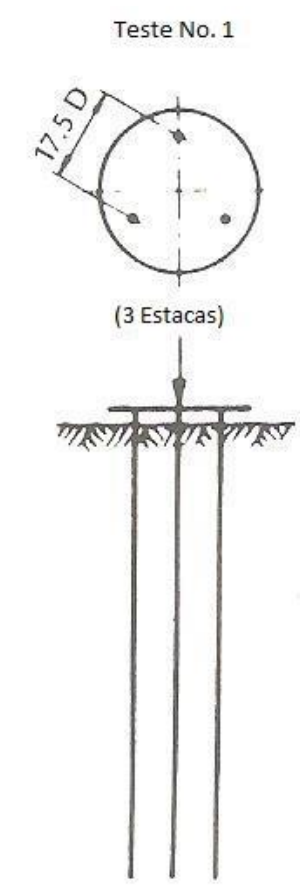

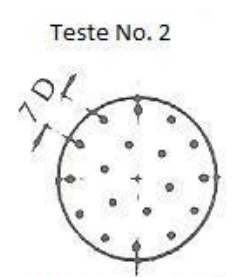

(18 Estacas Verticais)

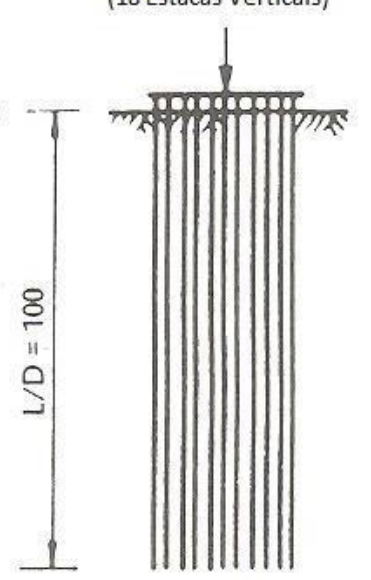

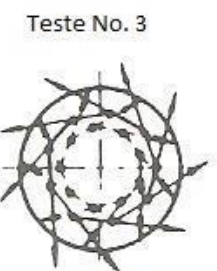

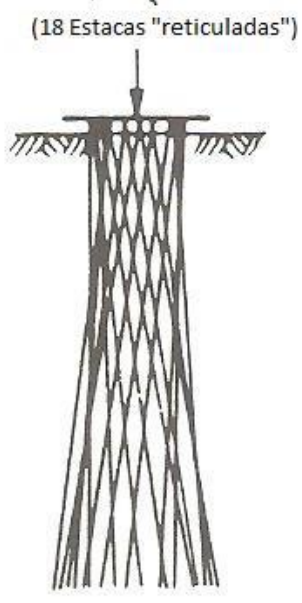

Arranjo das estacas nos modelos de teste

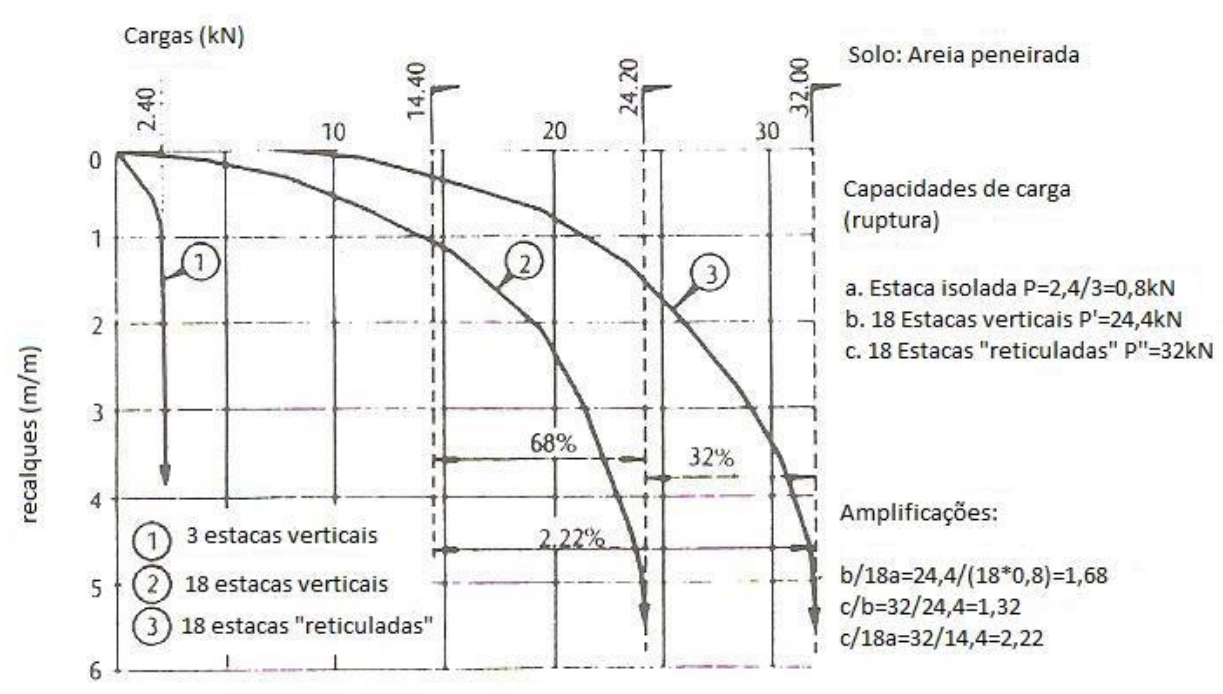

Resultados de provas de carga para estacas em areia grossa peneirada

Figura 2: Efeito da disposição das estacas raiz em reticulados em comparação com estacas verticais [3] 
Por ser executada com a sonda rotativa, que é um equipamento normalmente utilizado para extração de testemunhos de rocha, a estaca raiz possui a capacidade de perfurar materiais bastante competentes sob o ponto de vista geomecânico. Para tal, basta utilizar uma ferramenta que seja capaz de perfurar a rocha. A capacidade de perfurar materiais de alta resistência mecânica fez com que as estacas raiz sejam utilizadas para tensões de trabalho superiores aos demais tipos de estaca. Para esta finalidade podem ser utilizadas sapatas diamantadas (fig. 3), as quais atuam por abrasão fazendo a perfuração da rocha. Estas sapatas na maior parte das vezes permitem a formação de testemunhos no seu interior, devendo a composição de perfuração ser retirada do furo para remoção destes testemunhos periodicamente durante a perfuração. Como, para a execução de estacas 0 importante é que o furo esteja aberto para possibilitar a injeção da mesma e nem sempre o testemunho traz uma informação complementar relevante, buscaram-se meios de se perfurar a estaca em rocha sem a formação dos mesmos.

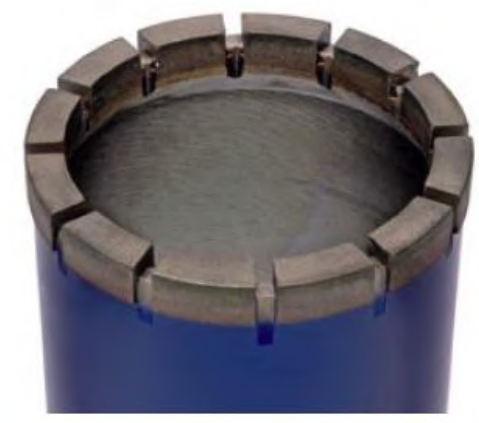

Figura 3: Sapata diamantada para perfuração de rocha [12].

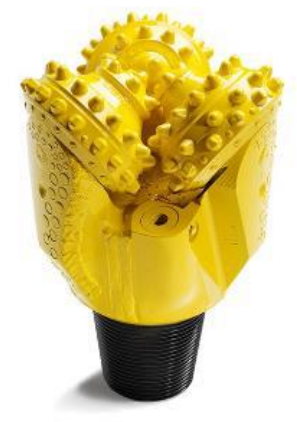

Figura 4: Roller bit [13]

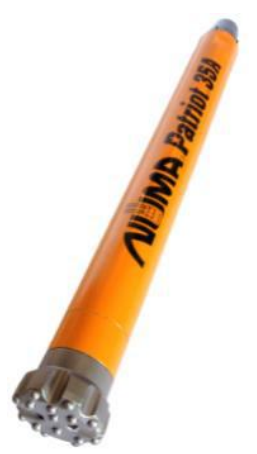

Figura 5: Martelo de Fundo com o bit de perfuração [14] 
Para este fim, foram estudados sistemas de perfuração com o uso de circulação reversa, onde a pressão do fluido traria os testemunhos até a superfície, foram estudadas ferramentas diamantadas que possibilitassem a perfuração da seção plena, surgiram os roller bits (fig. 4), muito utilizados na indústria do óleo e gás e que perfuram a rocha através da remoção de lascas da mesma através de seus dentes e surgiram também os martelos roto-percussivos. Estes martelos acionam uma ponta, chamada de bit, com botões de carbeto de tungstênio que fragmenta a rocha e estes fragmentos são trazidos para a superfície com ar comprimido. $O$ martelo em si pode se situar na mesa rotativa da perfuratriz, tendo sua energia transferida ao bit pelas hastes de perfuração. Este sistema somente é viável para diâmetros pequenos, pois exige que as hastes sejam dimensionadas para suportar os golpes do martelo. O martelo também pode estar posicionado no fundo do furo, sendo chamado de martelo de fundo ou DTH (down the hole) e acionando o bit diretamente (fig. 5). Os martelos de superfície podem ser acionados por ar comprimido ou hidraulicamente, enquanto os martelos de fundo são todos acionados por ar comprimido. Deve-se lembrar que as ferramentas de perfuração de rocha devem passar por dentro do revestimento utilizado para perfuração de solo, 0 que reduz o diâmetro da estaca. Por sua vez, o fluxo do fluido de perfuração em torno do revestimento faz com que o diâmetro acabado da estaca em solo seja superior ao diâmetro do revestimento e esta diferença de diâmetro deve ser levada em consideração no projeto.

Quando existem obstáculos que exigem o uso alternado de ferramentas para solo e rocha, como os matacões, por exemplo, pode-se iniciar a perfuração com um diâmetro maior, que permita a adoção de um martelo de fundo com diâmetro suficiente para a passagem do revestimento necessário para a garantia do diâmetro de projeto após o obstáculo. Ou, pode-se adotar um bit retrátil (fig.6), o qual é capaz de levar o revestimento de projeto através do obstáculo, mesmo que este obstáculo seja um bloco de rocha. Deve-se ter cuidado com o uso do martelo de fundo em regiões de aterro feito de modo descontrolado, pois o mesmo é um martelo de impacto e, por este motivo, não é adequado para a perfuração de concreto armado, não conseguindo perfurar as armaduras.

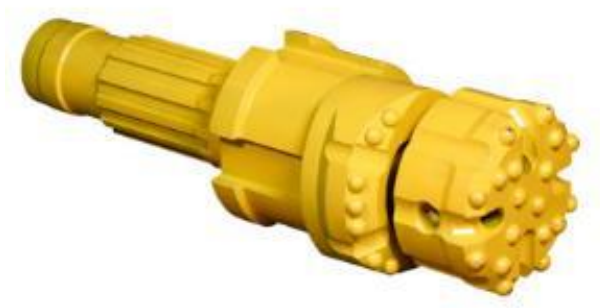

Figura 6: Bit retrátil para perfuração simultânea à instalação de revestimento [15]

A injeção de uma estaca raiz é feita com o uso de um tubo de injeção, que é colocado por dentro da armadura da estaca. Como não é possível o uso de um tubo de injeção de grande diâmetro, as mesmas são feitas com argamassa, que é bombeada por dentro deste tubo. Para possibilitar o bombeamento, esta argamassa é bastante fluida, o que leva a um alto consumo de cimento (mínimo de $600 \mathrm{~kg}$ por metro cúbico, conforme a NBR 6122 [9]). A argamassa é bombeada até que extravase argamassa sem impurezas pelo topo do revestimento. Quando isto 
ocorre, tem-se o tubo de revestimento cheio de argamassa limpa. Procede-se então à remoção do revestimento. À medida que os segmentos de revestimento são removidos, fecha-se o topo da composição e aplica-se pressão com a própria bomba ou com ar comprimido. Esta pressão deve ser anotada e é a pressão de injeção da estaca. Pelo fato do revestimento precisar ser fechado hermeticamente para permitir a aplicação da pressão de injeção e pelo fato da argamassa antes da injeção ser bastante fluida, a armadura de uma estaca raiz precisa se apoiar sobre o fundo do furo e isto leva à necessidade, por questões executivas, da estaca ser armada em todo o seu comprimento. Por ser uma estaca com tensão decorrente da carga de trabalho elevada, a armadura deve ser prevista como atuando contra a flambagem. A pressão aplicada tem como objetivo forçar a argamassa a subir lateralmente em volta do revestimento, garantindo que não entre lama ou detritos de perfuração quando o revestimento é removido e garantindo desta forma a integridade da estaca.

\section{Execução da obra de reforço}

Devido à altura da ponte e para facilitar o correto posicionamento das estacas no bloco, optou-se por executar as estacas do nível do rio, com equipamento apoiado sobre flutuantes. Inicialmente foram cravadas camisas metálicas, as quais penetraram no material inconsolidado do fundo do rio. Estas camisas têm a função de servir de forma para as estacas no trecho de lâmina d'água e aéreo, uma vez que os novos blocos foram executados acima do nível da água.

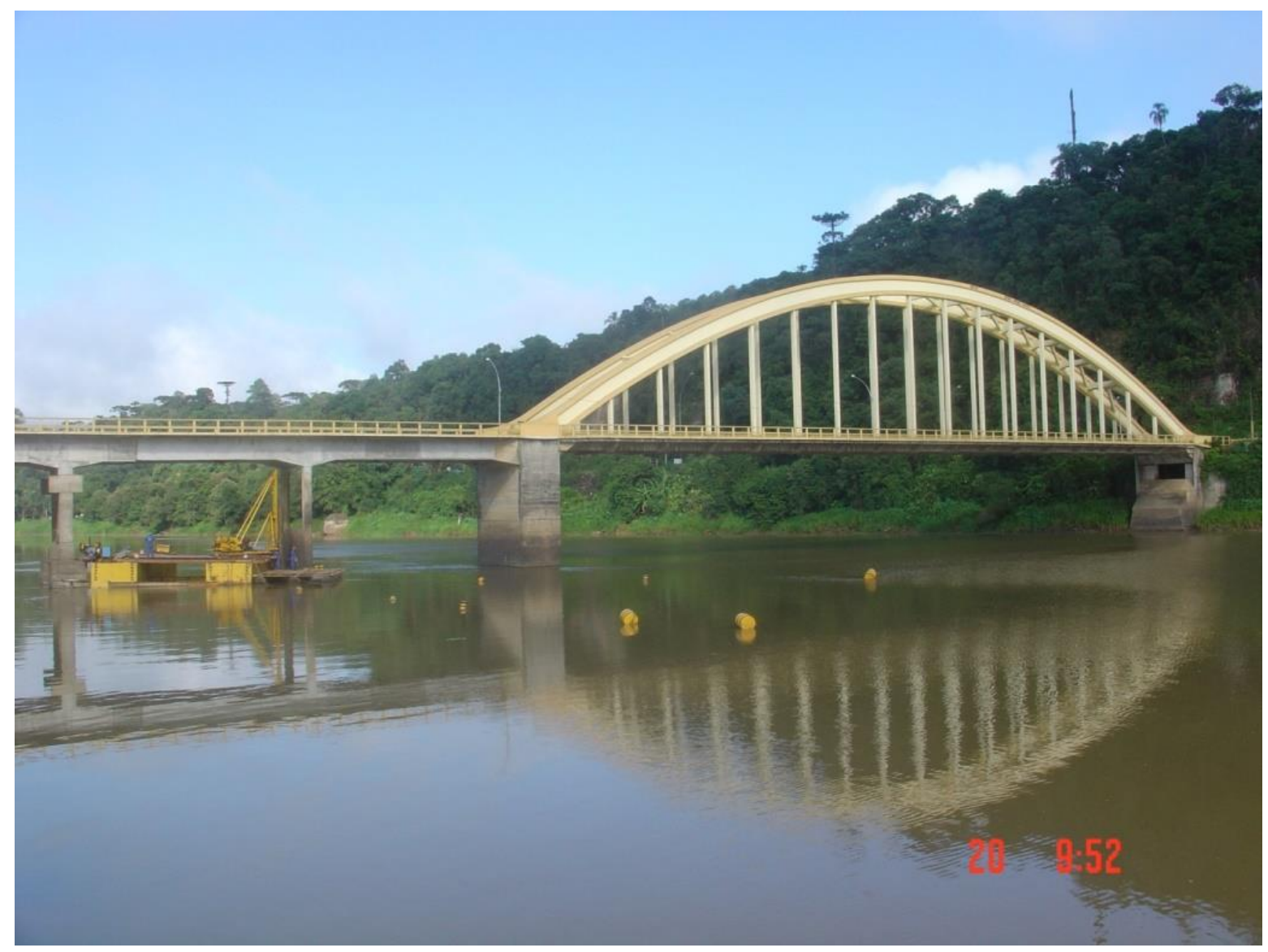

Figura 7: Vista da ponte com o bate-estaca trabalhando sob o seu tabuleiro [16]. 
As camisas foram cravadas com um bate-estaca com torre curta o suficiente para trabalhar abaixo do tabuleiro da ponte. As camisas foram emedadas com o uso de solda elétrica, pois o seu comprimento era superior à lâmina d'água somada ao trecho de solo do fundo do rio e ao trecho aéreo. Fotos deste trabalho podem ser vistas nas Figuras 7 e 8 . As camisas metálicas ficaram com comprimentos cravados entre 8,20 e 11,05 metros, apoiando-se sobre o topo rochoso.

Foram executadas estacas raiz por dentro das camisas já cravadas. Como as camisas apoiavam-se diretamente sobre a rocha, as estacas foram executadas diretamente com o martelo de fundo com diâmetro de $235 \mathrm{~mm}$. A figura 9 mostra ao fundo a perfuratriz executando as estacas e à frente o compressor responsável por suprir ar comprimido para operação do martelo de fundo. A figura 10 mostra a perfuratriz sendo posicionada sobre uma estaca a ser executada e a figura 11 mostra um detalhe da perfuratriz executando uma estaca raiz com o martelo de fundo.

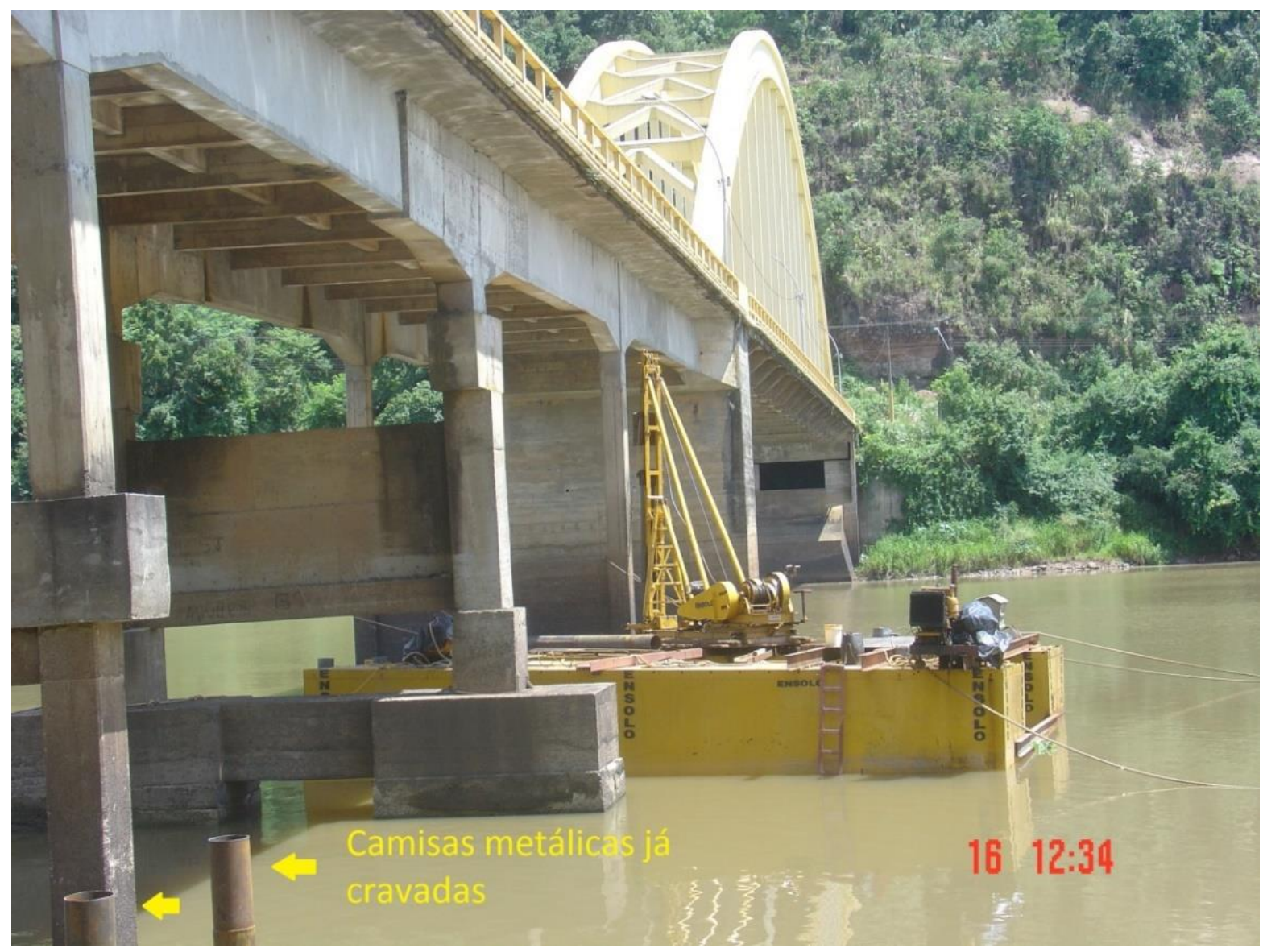

Figura 8: Vista da ponte com o bate-estaca cravando as camisas, com algumas camisas já cravadas aparentes [16].

Antes da execução do reforço do bloco anterior ao bloco sobre o qual se apoiava o arco, foi identificada a presença de um bloco de concreto na posição das estacas, o qual se concluiu depois ser a fundação de uma das torres sobre as quais passavam os cabos que suspendiam a forma do arco da ponte. Um engenheiro mergulhou com o objetivo de medir as dimensões deste bloco. As dimensões reais do bloco foram repassadas ao projetista do reforço de fundações com o objetivo de se 
verificar a viabilidade de se aumentar as dimensões do bloco de reforço. O projetista optou pela manutenção das dimensões do bloco de reforço, o que levou à necessidade de se perfurar o bloco em si. Foram executadas então sondagens rotativas com barrilete duplo móvel de diâmetro HW no ponto das estacas para se determinar a altura do bloco e verificar a existência de armadura nos mesmos. Concluiu-se que o bloco possuía entre 1,60 e 2,50 metros de altura e que era em concreto simples, não armado.

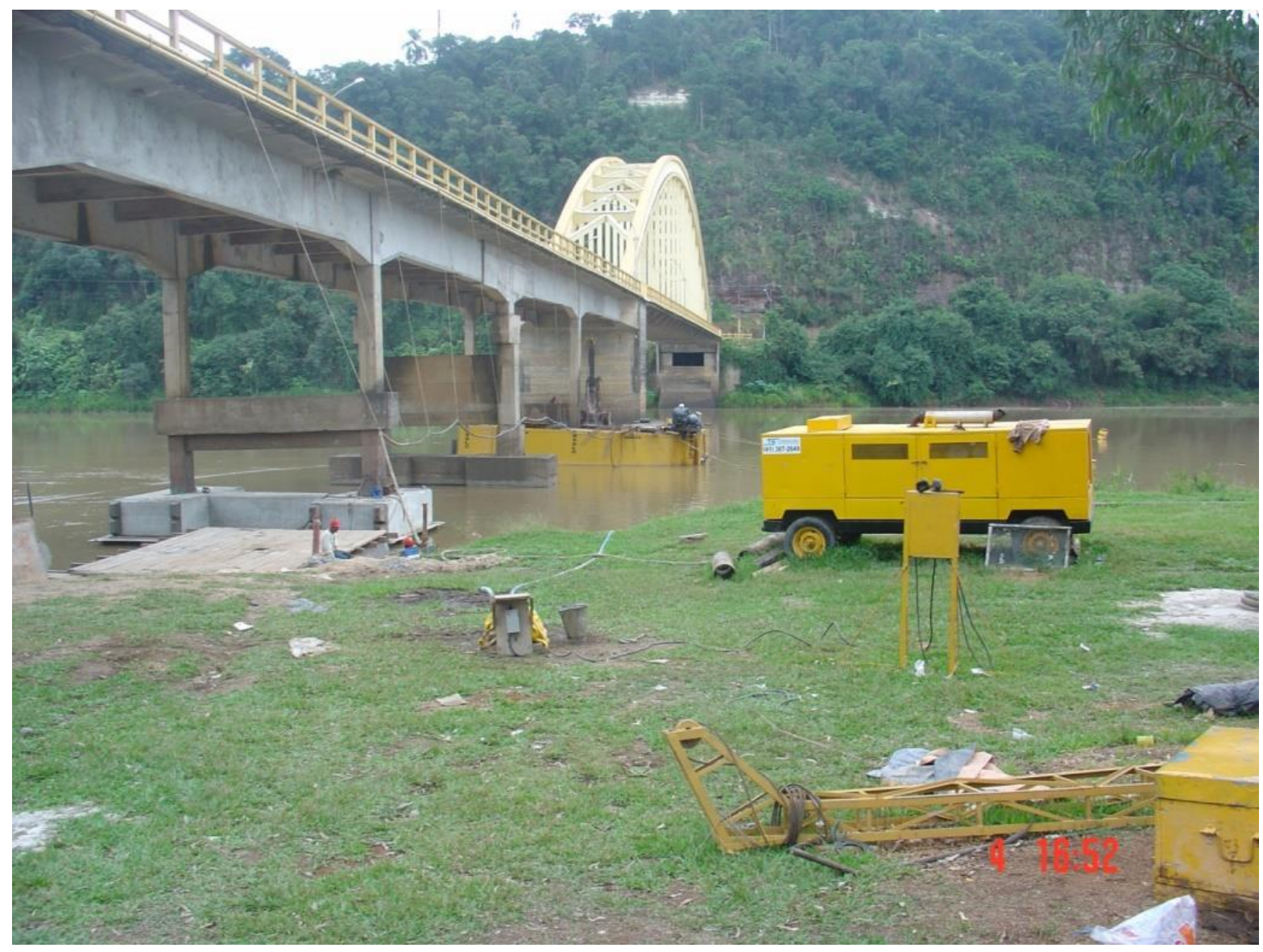

Figura 9: Vista da ponte com a perfuratriz trabalhando sobre flutuante, com o compressor de ar visível à frente e o bloco sobre as estacas raiz do primeiro pilar a partir da margem já executado [16].

A ferramenta utilizada para perfuração das estacas no trecho do bloco foi um barrilete simples feito especialmente para a obra, com sapata diamantada com diâmetro de dez polegadas $(254 \mathrm{~mm})$. Este diâmetro de furo feito no concreto é suficiente para permitir a execução das estacas raiz com o martelo de fundo de $235 \mathrm{~mm}$ na rocha subjacente. Foi escolhida a perfuração com sapata diamantada com o objetivo de não causar trincas no bloco, de modo a garantir a injeção e a integridade das estacas. Foi adotado um barrilete simples, ao invés de um barrilete duplo móvel pois a qualidade dos testemunhos não era relevante neste caso. A figura 12 mostra duas sapatas diamantadas do barrilete simples, sendo uma desgastada após o uso e a outra nova.

Após a execução das estacas, foram concretados blocos de coroamento sobre as mesmas. Estes blocos foram protendidos de modo a garantir a aderência com os 
pilares existentes. Os blocos foram concretados com tubos metálicos em volta dos revestimentos perdidos das estacas, permitindo a movimentação da estaca em relação ao bloco. As estacas foram colocadas sob carga com macacos reagindo contra os blocos, de modo a evitar recalques adicionais para que as estacas admitissem a carga de trabalho. Somente após as estacas serem colocadas em carga o espaço entre as estacas e os tubos foi preenchido com graute. A figura 13 mostra um detalhe das estacas com os tubos ao seu redor, que foram preenchidos posteriormente com graute.

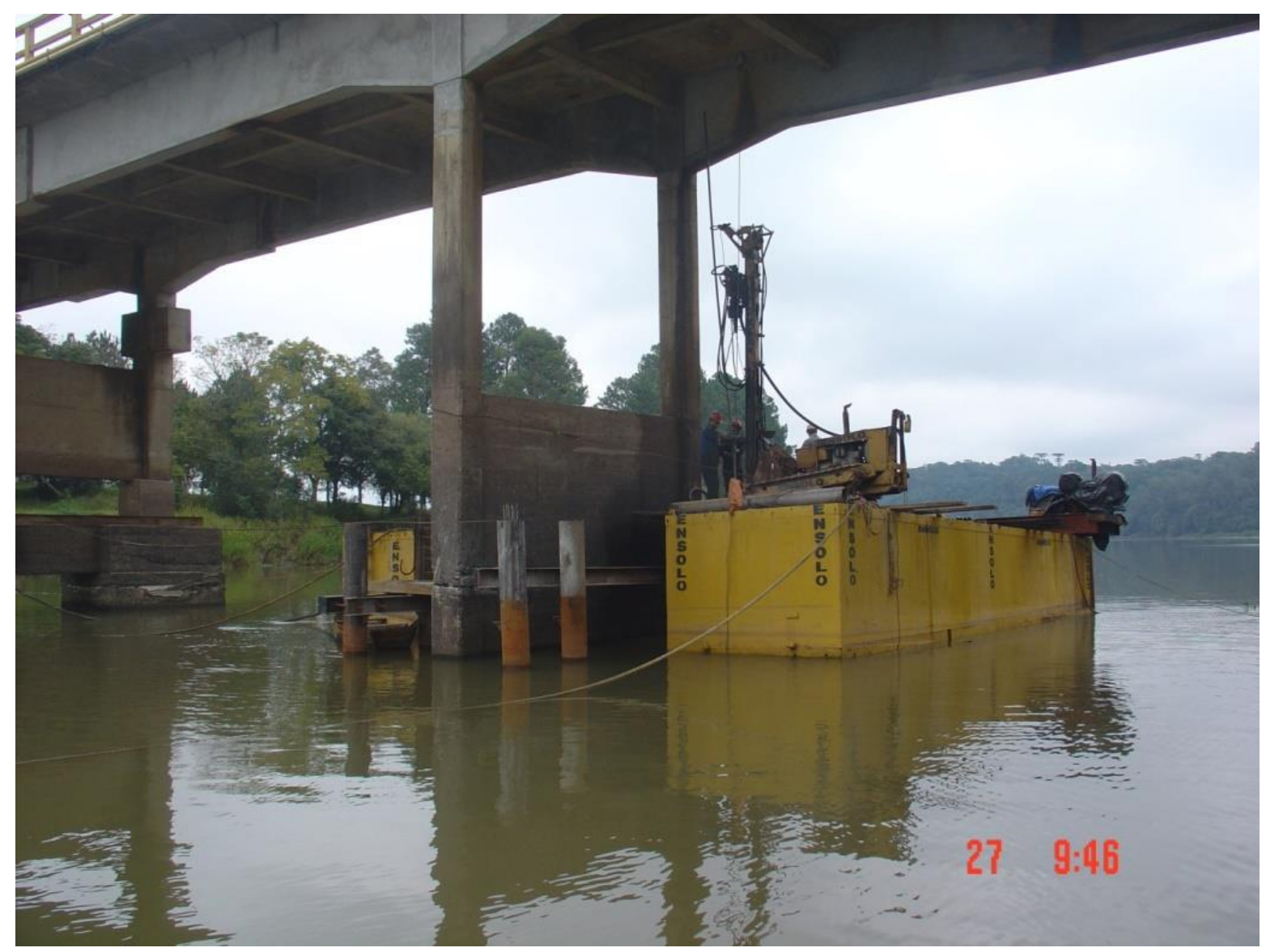

Figura 10: Perfuratriz sendo posicionada sobre uma estaca a ser perfurada. [16] 


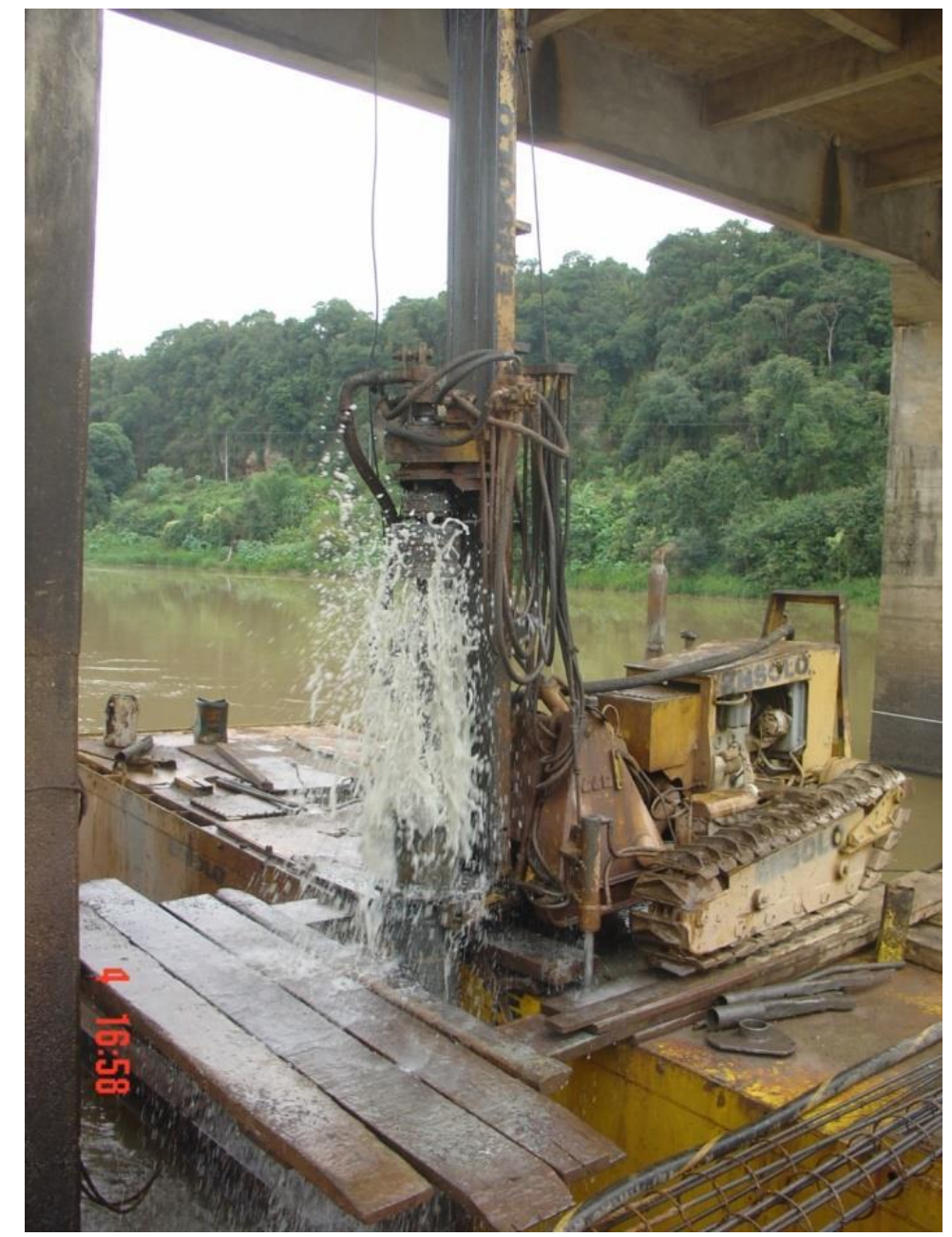

Figura 11: Detalhe da perfuratriz executando uma estaca com o uso do martelo de fundo [16].

Acima da cota destes blocos, foram incorporados consolos metálicos aos pilares. A figura 14 mostra a execução destes consolos. Estes consolos permitiram a ação de macacos hidráulicos, os quais reagiam contra os blocos recém-executados suportando os pilares. Os macacos foram posicionados e após os macacos suportarem o peso da ponte, os pilares foram seccionados um a um, os macacos ergueram os pilares de modo a renivelar a ponte e só então os pilares foram recompostos de modo a apoiar sobre os blocos novos. 


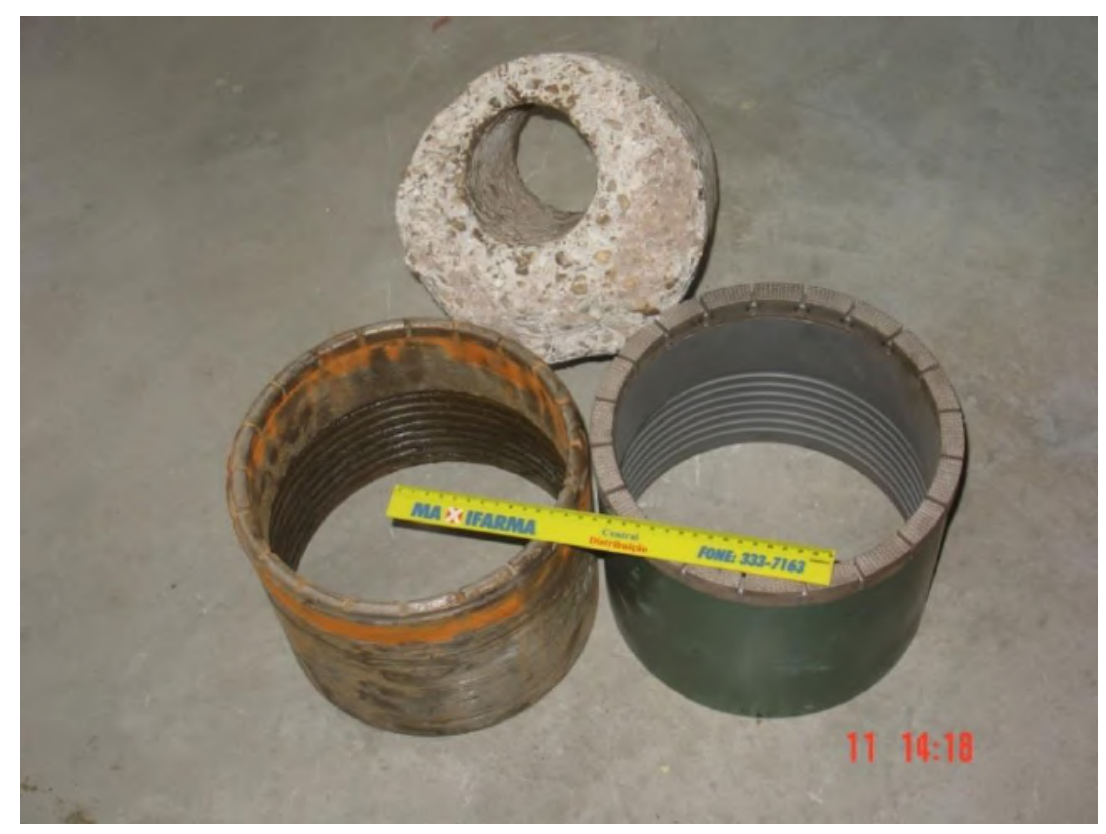

Figura 12: Sapatas usadas no barrilete simples com $254 \mathrm{~mm}$ de diâmetro, sendo a da esquerda desgastada após o uso e a da direita, nova. Ao fundo vê-se um testemunho obtido [16].

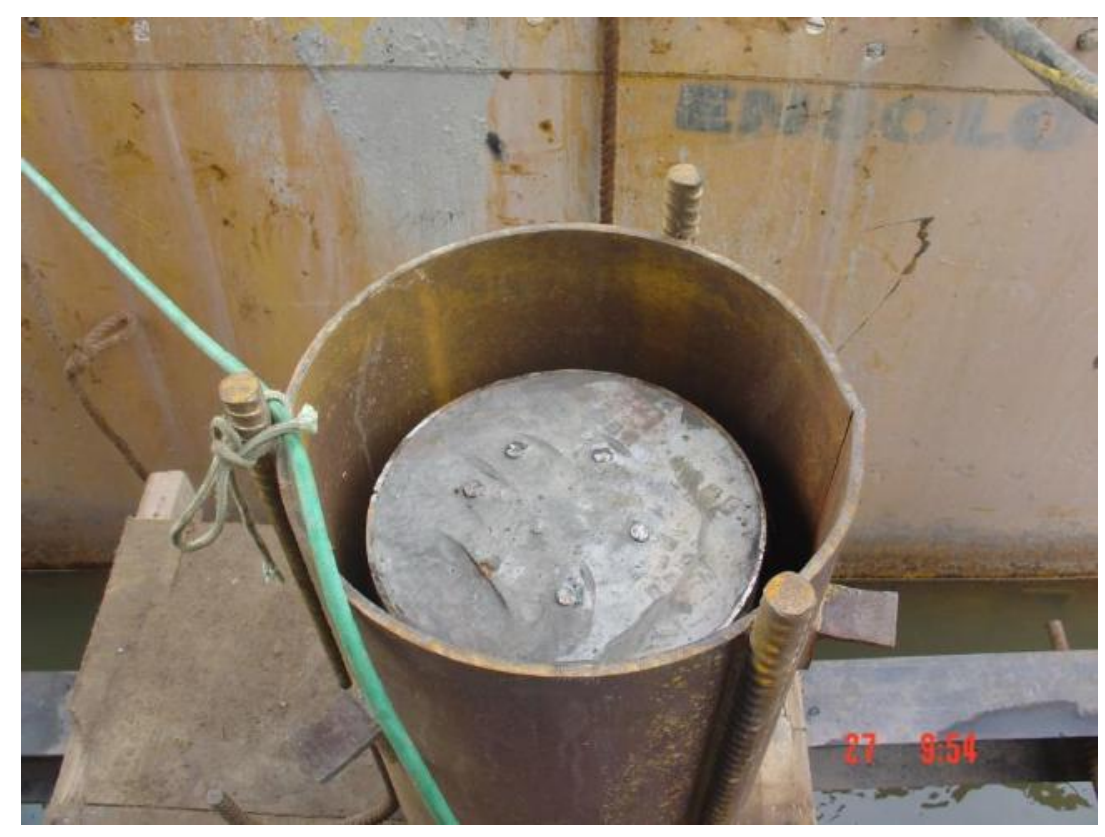

Figura 13: Detalhe de tubo colocado ao redor de estaca para permitir a suspensão do bloco reagindo contra a mesma e a instalação da estaca sob carga. O espaço entre o tubo e a estaca foi grauteado após a aplicação de carga à estaca. [16] 


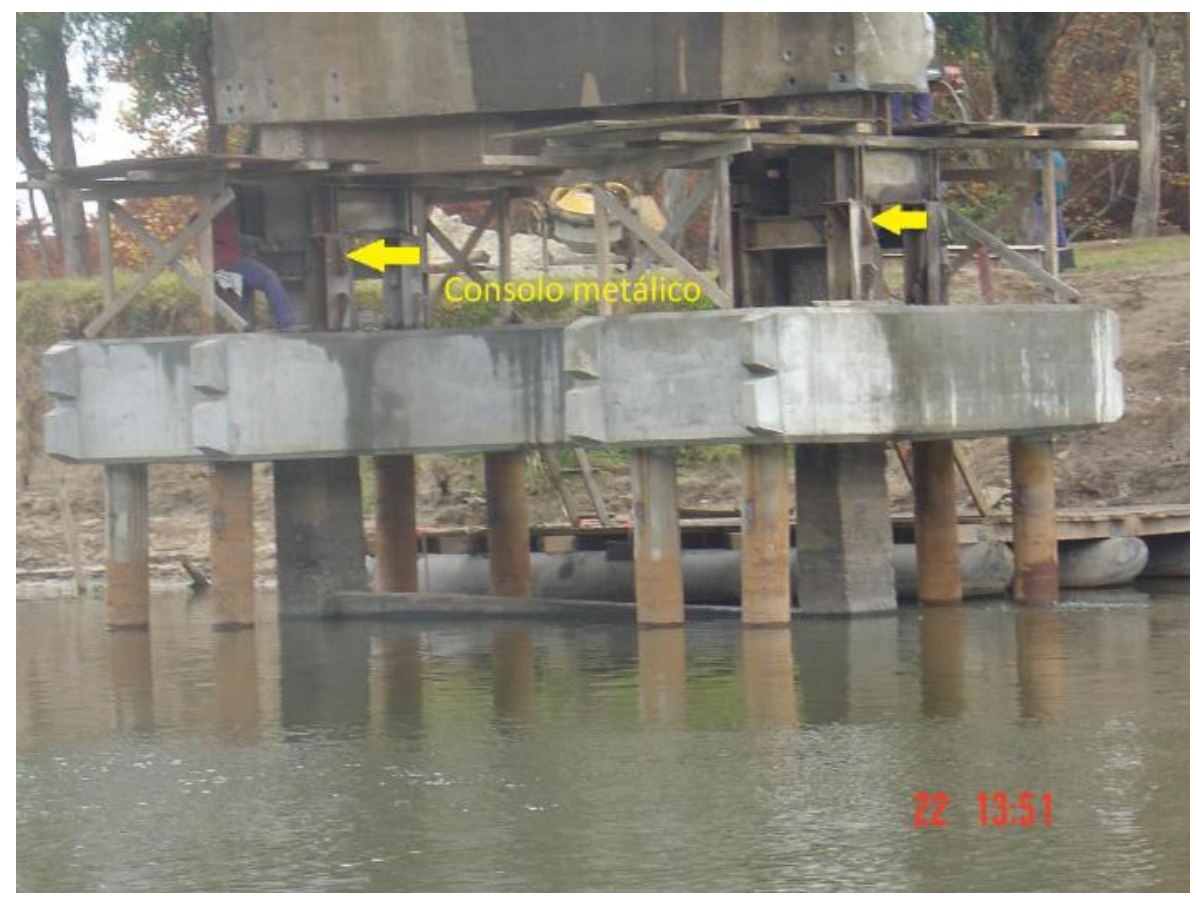

Figura 14: Execução dos consolos para permitir a ação dos macacos [16].

\section{Conclusões}

O reforço de fundações e renivelamento da ponte possibilitou que a mesma fosse reaberta ao tráfego, facilitando a logística de abastecimento da cidade de União da Vitória. Além do reparo estrutural, a ponte recebeu nova iluminação, melhorando a segurança do tráfego sobre a mesma.

\section{Agradecimentos}

Os autores gostariam de agradecer ao Engenheiro Raul Ozório de Almeida, da Construtora Roca Ltda, pelas informações a respeito da obra e por permitir a publicação das mesmas.

\section{Referências}

[1] Museu Histórico União da Vitória, acervo de fotos e vídeos.

[2] Sondagel Sondagens Geológicas Ltda (2006) Relatório de sondagens à percussão e rotativas número OSPR 2575-06.

[3] Lizzi, F. (1978). Reticulated Root Piles - to Correct Landslides. ASCE convenction, Chicago, October 16-20. Preprint 3370, 25 pp.

[4] Cambefort, H. (1975) Perforaciones y Sondeos. Ediciones Omega, S.A., Barcelona, Espanha. Tradução para o Espanhol do original Forages et Sondages por Angel Rodríguez Paradinas. 3ª edição. 
[5] Geofix Fundações (2017) Estacas raiz. Método Executivo e Cuidados na Execução. Disponível em http://www.geofix.com.br/servico-estaca-raiz.php em 20/04/2017.

[6] CZM Foundation Equipment (2017) Equipamentos para estacas raiz e tirantes, disponível em http://czm.com.br/index.php/estaca-raiz-tirante/ em 27/02/2017.

[7] Soilmec do Brasil S.A. (2017) Equipamentos para microestacas e ancoragens, disponível

em http://www.soilmec.com.br/site/index.php?option=com content\&view=article\&id $=182 \&$ Itemid=367\&lang=pt em 27/02/2017.

[8] CMV Brasil Ltda (2017) Equipamentos para estacas raiz, tirantes e jet grouting, disponível em http://www.cmvbrasil.com.br/website113/institucionais.php?cod pag=319 em 27/02/2017.

[9] Associação Brasileira de Normas Técnicas, (2010). NBR 6122, Projeto e Execução de Fundações. Rio de Janeiro, Brasil.

[10] Sodré, D. J. R., Cintra, J. C. A., Albiero, J. H., Carvalho, D. (1994).Previsão da Carga última de estacas raiz através de formulas empíricas. X Congrsso Brasileiro de Mecânica dos Solos e Engenharia de Fundações, $X$ COBRAMSEF, Anais, Volume 1, pp. 263-270. Foz do Iguaçu.

[11] Cabral, D. A. (1986) O uso da estaca raiz como fundação de obras normais. In: CONGRESSO BRASILEIRO DE MECÂNICA DOS SOLOS E ENGENHARIA DE FUNDAÇÕES, 8., 1986, Porto Alegre. Anais... Porto Alegre: ABMS, 1986. v. 6 , p. $71-82$

[12] Atlas Copco Exploration Products (2008). Craelius ${ }^{\mathrm{TM}}$ exploration drilling tools catalog. Märsta, Suécia.

[13] Atlas Copco (2017). Epsilon bits. Disponível em http://www.atlascopco.us/enus/mrba/products/rock-drilling-tools/rotary-drilling-tools/rotary-bits/Triconebits/Omega-tricone-bits em 27/02/2017.

[14] Numa (2017). Patriot 35A Down the Hole Hammer. Catálogo obtido a partir do website http://www.numahammers.com/hammer-specifications/ em 27/02/2017.

[15] Atlas Copco (2017). Casing advancement systems. Disponível em http://www.atlascopco.us/en-us/mrba/products/rock-drilling-tools/geotechnicaldrilling-tools/casing-advancement-systems em 27/02/2017.

[16] ENSOLO Engenharia de Solos e Fundações (2006). Relatório fotográfico da obra número 2675. 